\title{
An inverse association between the Mediterranean diet and bladder cancer risk: a pooled analysis of 13 cohort studies
}

\author{
Willem J. A. Witlox • Frits H. M. van Osch ${ }^{1,2}$ - Maree Brinkman ${ }^{1,3,11}$. Sylvia Jochems ${ }^{1,2}$ - Maria E. Goossens ${ }^{4}$. \\ Elisabete Weiderpass ${ }^{5,6,7,8}$. Emily White ${ }^{9}$. Piet A. van den Brandt ${ }^{10}$. Graham G. Giles ${ }^{11,12} \cdot$ Roger L. Milne ${ }^{11,12}$. \\ Inge Huybrechts ${ }^{13} \cdot$ Hans-Olov Adami ${ }^{14,15} \cdot$ Bas Bueno-de-Mesquita $^{16,17,18,19} \cdot$ Anke Wesselius $^{1}$ (1) \\ Maurice P. Zeegers ${ }^{1,2,20}$
}

Received: 18 October 2018 / Accepted: 20 January 2019 / Published online: 8 February 2019

(c) The Author(s) 2019

\begin{abstract}
Purpose The role of diet in bladder carcinogenesis has yet to be established. To date most studies have investigated dietary components individually, rather than as dietary patterns, which may provide stronger evidence for any influence of diet on bladder carcinogenesis. The Mediterranean diet has been associated with many health benefits, but few studies have investigated its association with bladder cancer risk.

Methods We investigated the potential association between the Mediterranean diet score (MDS) and risk of developing bladder cancer by pooling 13 prospective cohort studies included in the BLadder cancer Epidemiology and Nutritional Determinants (BLEND) study and applying a Cox regression analysis.

Results Dietary data from 646,222 study participants, including 3639 incident bladder cancer cases, were analysed. We observed an inverse association between Mediterranean diet and bladder cancer risk ( $\mathrm{HR}_{\text {high }} 0.85$ [95\% CI 0.77, 0.93]). When stratifying the results on non-muscle-invasive or muscle-invasive disease or sex the association remained similar and the HR estimate was consistently below 1.00 both for medium and high adherence to the Mediterranean diet. A consistent association was observed when disregarding fat or alcohol intake.

Conclusion We found evidence that adherence to the Mediterranean diet was associated with reduced risk of developing bladder cancer, suggesting a positive effect of the diet as a whole and not just one component.
\end{abstract}

Keywords Mediterranean diet $\cdot$ Bladder cancer $\cdot$ Bladder cancer risk $\cdot$ Epidemiology

$\begin{array}{ll}\text { Abbreviations } \\ \text { BLEND } & \begin{array}{l}\text { BLadder cancer Epidemiology and Nutri- } \\ \text { tional Determinants }\end{array} \\ \text { 95\% CI } & \begin{array}{l}95 \% \text { confidence interval } \\ \text { European Prospective Investigation into } \\ \text { Cancer and Nutrition }\end{array} \\ \text { EPIC } & \text { Food Frequency Questionnaire } \\ \text { FFQ } & \text { Hazard ratio } \\ \text { HR } & \text { Melbourne Collaborative Cohort Study } \\ \text { MCCS } & \text { Muscle-invasive bladder cancer } \\ \text { MIBC } & \text { Non-muscle-invasive bladder cancer } \\ \text { NMIBC } & \end{array}$

Frits H. M. van Osch has equally contributed to this work as first author.

Anke Wesselius

anke.wesselius@maastrichtuniversity.nl

Extended author information available on the last page of the article
OR Odds ratio

TNM stage Tumour nodes metastasis stage

\section{Introduction}

Bladder cancer is the sixth leading cancer in the USA, with an estimated 81,190 new cases and 17,240 deaths in 2018 . Over $75 \%$ of all patients are still alive after 5 years [1]. Moreover, bladder cancer has high recurrence and is the most expensive malignancy to treat, accounting for $>3 \%$ of all cancer-related medical payments in the USA [2]. At present the better established risk factors associated with developing bladder cancer include smoking, age, male sex, occupation, and to a lesser extent obesity and physical inactivity [3-5]. Since most of the metabolites of ingested food come into direct contact with the bladder mucosa, diet might also play a role in the development of bladder cancer [6]. 
Previous studies of diet-related bladder cancer risk factors have tended to focus on single food items [7, 8]. For example, the Multiethnic Cohort (MEC) study, which included a total of 185,885 participants and 1137 incident bladder cancer cases, reported a hazard ratio (HR) of $0.40(95 \% \mathrm{CI}$ 0.23-0.69) comparing highest and lowest quartiles of vegetable intake [9]. Also, the Los Angeles Bladder Cancer (case-control) Study involving 3246 participants, including 1660 cases, reported a positive association between intake of red meat (salami, pastrami and beef) and bladder cancer risk (comparing highest and lowest quintile: OR 1.33, 95\% CI 1.02-1.74) [10]. Emerging evidence suggests that total dietary patterns may provide stronger evidence for diet-disease associations than individual dietary items [11].

The Mediterranean diet has been reported to be effective for preventing non-communicable diseases [12-15] and reducing overall mortality and the incidence of several cancers $[16,17]$. It is generally characterized by a high consumption of fruits, vegetables, legumes and cereals, moderate-to-high consumption of fish, moderate consumption of alcohol (mostly wine), low-to-moderate consumption of milk and dairy products, and low consumption of meat and meat products [18]. The diet distinguishes itself from other dietary recommendations and indices such as the Healthy Eating Index [19], the World Cancer Research Fund and American Institute for Cancer Research (WCRF/AICR) diet recommendations [20] and the Diet Inflammatory Index [21], by its higher levels of dietary fat, mainly monounsaturated fat from olive oil, and higher alcohol consumption, mainly from wine, although alcohol is a risk factor for several cancers [22-26].

To date, few studies [27, 28] have investigated the association between Mediterranean diet and bladder cancer. The European Prospective Investigation into Cancer and Nutrition (EPIC) cohort study, including 477,312 participants (of which 1425 were incident cases), found an inverse but nonsignificant association comparing a high with a low Mediterranean diet score (MDS) and urothelial cell carcinoma (UCC) overall (HR 0.84 [95\% CI 0.69, 1.03]), and for risk of aggressive (HR 0.88 [95\% CI $0.61,1.28]$ ) and non-aggressive disease (HR 0.78 [95\% CI 0.54, 1.14]). The association was statistically significant for current smokers (HR 0.66 [95\% CI 0.47, 0.93]) [27]. Researchers from the Melbourne Collaborative Cohort Study (MCCS), which included 37,442 participants at time of recruitment (379 incident cases), reported an inverse association for both sexes between the MDS and invasive UCC (HR 0.86 [95\% CI 0.74, 1.00]) [28].

Our primary aim was to build on the results of the EPIC cohort study and the MCCS, and to investigate prospectively the potential association between Mediterranean diet and the risk of developing bladder cancer, by aggregating data from 13 cohort studies in a pooled analysis using a metaanalysis approach. Our secondary aims were to examine heterogeneity in any association by sex and disease sub-type (non-muscle-invasive and muscle-invasive bladder cancer).

\section{Materials and methods}

\section{Study population}

Data were analysed from the Bladder cancer Epidemiology and Nutritional Determinants (BLEND) study. BLEND is a large international nutritional consortium, which included 16 cohort studies conducted in several countries. Thirteen of the 16 cohort studies had sufficient information on food items to be eligible for inclusion in our study on adherence to the Mediterranean diet and the risk of developing bladder cancer. Studies originated from centres in Denmark [29], France [30], Germany [31], Greece [32], Italy [32, 33], The Netherlands [34], Norway [35], Spain [32], Sweden [36-38] United Kingdom [39, 40], the USA [41], and Australia [42, 43].

\section{Data collection and coding}

Details on the methodology of the BLEND consortium have been described elsewhere [44]. Briefly, the primary data from all included studies were incorporated into one dataset. All data provided were checked and converted from daily, monthly, or yearly food intake to weekly intake, and intakes by portion were also converted to intake by grams. Data on bladder cancer diagnosis were mainly ascertained by self-reported questionnaires. Dietary data, collected using food frequency questionnaires in all studies, were recoded using the Eurocode 2 food coding system [45]. In addition to information on dietary intake, the BLEND data also included study characteristics (design, method of dietary assessment, recall time of dietary intake and geographical region), participant demographics (age, sex, and ethnicity), bladder cancer pathology (non-muscle-invasive and muscleinvasive disease), and smoking status (current/former/never) all measured at baseline.

\section{Mediterranean diet score}

To measure the degree of adherence to the Mediterranean diet, we used a nine-point scale that was constructed by Trichopoulou et al. [46]. Nine food items were included, namely, consumption of (1) cereals, (2) fruits and nuts, (3) vegetables, (4) legumes, (5) fish, (6) meat, (7) dairy products, (8) fats, and (9) alcohol/ethanol. For each component, a value of 0 or 1 was assigned using its sex-specific median for each study as a cutoff value. For the presumed beneficial components (vegetables, legumes, fruits and nuts, cereals, and fish), a value of 0 was assigned to those consuming less 
than the median cutoff, and a value of 1 was assigned to those consuming as much as the median cutoff or more. For the presumed detrimental components (meat and dairy products), a value of 1 was assigned to those consuming less than the median cutoff, and a value of 0 was assigned to those consuming as much as the median cutoff or more. For alcohol, a value of 1 was assigned to men consuming between 70 and $350 \mathrm{~g}$ per week and to women consuming between 35 and $175 \mathrm{~g}$ per week. We assumed that one portion of alcohol of any type contained a standard amount of $10 \mathrm{~g}$ of ethanol. For fat intake, we calculated the ratio of fats from plant sources to total fat and assigned a value of 0 to those consuming less than the median cutoff, and a value of 1 to those consuming as much as the median cutoff or more. We used the ratio of plant-to-total fat because we hypothesized that the effect of dietary fat may depend on its source and not solely on the quantity consumed. For example, monounsaturated fat is present in both olive oil and animal products, and by just summing up the total amount of monounsaturated fat consumed it may not take into account the potentially different biological responses related to dietary source.

The MDS ranged from 0 (minimal adherence) to 9 (maximal adherence). Scores between 0 and 3 were classified as "low adherence", scores of 4 and 5 were classified as "medium adherence", and scores of 6 or higher were classified as "high adherence".

\section{Statistical analysis}

Cox proportional hazard models using age at recruitment as the starting point on the time scale were used to calculate HRs and 95\% confidence intervals (95\% CI) for developing bladder cancer, comparing medium and high adherence with low adherence. The MDS was also analysed as a continuous variable (0-9). The proportional hazards assumption was examined through Schoenfeld residuals [47]. When considering all included participants, the assumption of proportional hazards was violated and therefore we compared the association between MDS score and risk of bladder cancer in all subjects younger than 70 years and in those older than 70 years to assess to what degree the HR changed over time. The Cox regression models were all adjusted for total energy intake in kilocalories (by applying a restricted cubic spline), sex and smoking status (never, former or current smoker). Furthermore, survival time was estimated by subtracting age at exit by age at entry in the cohort as $T_{0}$, thereby correcting for age in the analysis and also the study sample from which the cases originated was corrected for by introducing study ID as a random effect. Analyses were stratified on sex and disease sub-type (non-muscle-invasive or muscle-invasive disease). To test for residual confounding by smoking, the association between MDS score and risk of bladder cancer was also investigated while stratifying for smoking status (ever/never).

Additionally, unstratified analyses were repeated to determine the effect of both alcohol and fats as two distinctive features of Mediterranean diet, with alterations to the estimation of the MDS in an exploratory analysis. To test the effect of alcohol on the MDS, we excluded the alcohol component from the diet score. For fats, we repeated the analysis by excluding fats from the diet score altogether and by replacing the lipid ratio (fats from plant sources divided by total fats) with only olive oil intake. All statistical analyses were performed using Stata/SE 14.2 [48].

\section{Results}

Dietary data from 646,222 study participants, including 3639 incident cases and 642,583 non-cases were analysed. Disease sub-type was known for 2425 cases, of which 945 (39\%) were muscle-invasive bladder cancer (MIBC) and $1480(61 \%)$ were non-muscle-invasive bladder cancer (NMIBC). Compared with non-cases, bladder cancer cases were more likely to be male (74\%) and to be current or former smokers (79\%). Of all cases, $22 \%$ originated from Scandinavian countries, $12 \%$ from Mediterranean regions, and $42 \%$ from other countries in Western Europe. The remaining $24 \%$ of the cases were living in the USA (10\%) or Australia (14\%); the Australian study (MCCS) oversampled people born in Greece or Italy [42, 43] (Table 1).

The overall HR estimates for bladder cancer associated with MDS, after adjustment for total energy intake, smoking status, and sex, are presented in Table 2. A total of 6,577,179 person years, including 3581 cases, were analysed. Overall, high adherence to the Mediterranean diet was associated with a decrease in bladder cancer risk compared with low adherence $\left(\mathrm{HR}_{\text {high }} 0.85\right.$ [95\% CI 0.77, 0.93]). A decreased bladder cancer risk was also found for medium compared with low adherence to the Mediterranean diet $\left(\mathrm{HR}_{\text {medium }} 0.91\right.$ [95\% CI 0.85, 0.99]). In addition, an inverse linear association was found between a one-unit increase in adherence to the Mediterranean diet and risk of developing bladder cancer ( $\mathrm{HR}_{\text {continuous }} 0.96$ [95\% CI 0.94, 0.98]). Although the proportional hazards assumption was violated, the results were similar when considering only those younger than 70 years at entry in the study $\left(\mathrm{HR}_{\text {high }} 0.80\right.$, [95\% CI 0.72 , 0.89 ], $\mathrm{HR}_{\text {medium }} 0.90$, [95\% CI $\left.0.83,0.98\right]$ ) separately from those older than 70 years at entry in the study $\left(\mathrm{HR}_{\text {high }} 0.86\right.$, [95\% CI 0.57, 1.29], $\mathrm{HR}_{\text {medium }} 0.82$, [95\% CI 0.60, 1.14]), indicating that the presented HRs in Tables 2 and 3 were probably not heavily influenced by this violation. Furthermore, residual confounding by smoking seemed minimal as the results in never smokers $\left(\mathrm{HR}_{\text {high }} 0.84\right.$, [95\% CI 0.68 , 1.04 ], $\mathrm{HR}_{\text {medium }} 0.84$, [95\% CI 0.71, 0.99]) were similar to 
Table 1 Characteristics of the 13 eligible studies according to subject status, sex, age, TNM stage, and smoking status

\begin{tabular}{|c|c|c|c|c|c|c|c|c|c|c|c|c|c|c|c|}
\hline \multirow[t]{2}{*}{ Study } & & \multicolumn{2}{|l|}{$\begin{array}{l}\text { Denmark } \\
\text { (EPIC) }\end{array}$} & \multicolumn{2}{|c|}{ France (EPIC) } & \multicolumn{2}{|l|}{$\begin{array}{l}\text { Germany } \\
\text { (EPIC) }\end{array}$} & \multicolumn{2}{|c|}{ Greece (EPIC) } & \multicolumn{2}{|c|}{ Italy (EPIC) } & \multicolumn{2}{|c|}{$\begin{array}{l}\text { The Nether- } \\
\text { lands (EPIC) }\end{array}$} & \multicolumn{2}{|l|}{$\begin{array}{l}\text { Norway } \\
\text { (EPIC) }\end{array}$} \\
\hline & & No. & $\%^{\mathrm{a}}$ & No. & $\%^{\mathrm{a}}$ & No & $\%^{a}$ & No. & $\%^{\mathrm{a}}$ & No. & $\%^{a}$ & No. & $\%^{\mathrm{a}}$ & No. & $\%^{\mathrm{a}}$ \\
\hline \multicolumn{16}{|l|}{ Subject status } \\
\hline \multicolumn{2}{|l|}{ Total } & 56,005 & 100 & 64,866 & 100 & 49,457 & 100 & 25,268 & 100 & 45,204 & 1003 & 37,102 & 100 & 33,856 & 100 \\
\hline \multicolumn{2}{|l|}{ Cases } & 411 & $<1$ & 31 & $<1$ & 218 & $<1$ & 50 & $<1$ & 192 & $<1$ & 119 & $<1$ & 24 & $<1$ \\
\hline \multicolumn{2}{|l|}{ Non-cases } & 55,594 & $>99$ & 64,835 & $>99$ & 49,239 & $>99$ & 25,218 & $>99$ & 45,012 & $>99$ & 36,983 & $>99$ & 33,832 & $>99$ \\
\hline Sex & & & & & & & & & & & & & & & \\
\hline Men & & 26,764 & 48 & 0 & 0 & 21,551 & 44 & 10,438 & 41 & 14,084 & 31 & 9801 & 26 & 0 & 0 \\
\hline Women & & 29,241 & 52 & 64,866 & 100 & 27,906 & 56 & 14,830 & 59 & 31,120 & 692 & 27,301 & 74 & 33,856 & 100 \\
\hline Age & & & & & & & & & & & & & & & \\
\hline$<50$ & & 0 & 0 & 27,158 & 42 & 23,661 & 48 & 10,715 & 42 & 21,565 & $48 \quad 1$ & 16,161 & 43 & 21,301 & 63 \\
\hline $50-59$ & & 40,996 & 73 & 26,392 & 41 & 16,978 & 34 & 5542 & 22 & 17,791 & $39 \quad 1$ & 14,720 & 40 & 12,555 & 37 \\
\hline $60-69$ & & 15,009 & 27 & 11,286 & 17 & 8817 & 18 & 6455 & 26 & 5647 & 13 & 6217 & 17 & 0 & 0 \\
\hline$\geq 70$ & & 0 & 0 & 30 & $<1$ & 1 & $<1$ & 2556 & 10 & 201 & $<1$ & 4 & $<1$ & 0 & 0 \\
\hline TNM stage & & & & & & & & & & & & & & & \\
\hline Invasive & & 44 & 24 & 5 & 12 & 40 & 26 & N/A & N/A & 20 & 20 & 23 & 20 & N/A & N/A \\
\hline Non-invasi & & 138 & 76 & 22 & 78 & 114 & 74 & N/A & N/A & 104 & 80 & 93 & 80 & N/A & N/A \\
\hline Smoking sta & & & & & & & & & & & & & & & \\
\hline Never smo & ker & 19,624 & 35 & 45,797 & 71 & 22,658 & 46 & 14,060 & 56 & 20,540 & 45 & 14,171 & 38 & 12,057 & 36 \\
\hline Former sm & loker & 17,070 & 31 & 13,121 & 20 & 16,386 & 33 & 4232 & 17 & 12,096 & 27 & 11,572 & 31 & 10,438 & 31 \\
\hline Current sm & noker & 19,311 & 34 & 5948 & 9 & 10,413 & 21 & 6976 & 27 & 12,568 & 28 & 11,359 & 31 & 11,361 & 33 \\
\hline MDS & & & & & & & & & & & & & & & \\
\hline $0-3$ & & 12,595 & 22 & 30,882 & 48 & 19,758 & 40 & 6895 & 27 & 13,935 & 31 & 16,255 & 44 & 12,147 & 36 \\
\hline $4-5$ & & 25,549 & 46 & 28,380 & 44 & 22,919 & 46 & 12,073 & 48 & 23,186 & 51 & 16,484 & 44 & 15,600 & 46 \\
\hline $6-9$ & & 17,861 & 32 & 5604 & 8 & 6780 & 14 & 6300 & 25 & 8083 & 18 & 4363 & 12 & 6109 & 18 \\
\hline Study & Spain (I & (EPIC) & & veden $(\mathrm{E})$ & PIC) & $\begin{array}{l}\text { United } \\
\text { (EPIC) }\end{array}$ & Kingdom & & USA (VI & ГAL) & Nether & rlands (N & LCS) & $\begin{array}{l}\text { Australia } \\
\text { (MCCS) }\end{array}$ & \\
\hline & No. & $\%^{\mathrm{a}}$ & $\mathrm{N}$ & & $\%$ & No. & $\%^{\mathrm{a}}$ & & No. & $\%^{\mathrm{a}}$ & No. & $\%^{\mathrm{a}}$ & & No. & $\%^{\mathrm{a}}$ \\
\hline Subject status & & & & & & & & & & & & & & & \\
\hline Total & 40,782 & 100 & &, 328 & 100 & 75,035 & 100 & & 76,433 & 100 & 5,632 & 100 & & 38,263 & 100 \\
\hline Cases & 154 & $<1$ & 30 & & $<1$ & 250 & $<1$ & & 378 & $<1$ & 940 & 17 & & 520 & 1 \\
\hline $\begin{array}{l}\text { Non- } \\
\text { cases }\end{array}$ & 40,628 & $>99$ & &, 025 & $>99$ & 74,785 & $>99$ & & 76,055 & $>99$ & 4692 & 83 & & 37,743 & 99 \\
\hline Sex & & & & & & & & & & & & & & & \\
\hline Men & 15,439 & 38 & &, 546 & 46 & 22,476 & 30 & & 36,792 & 52 & 3052 & 54 & & 15,798 & 41 \\
\hline Women & 25,343 & 62 & &, 782 & 54 & 52,559 & 70 & & 40,089 & 48 & 2580 & 46 & & 22,465 & 59 \\
\hline Age & & & & & & & & & & & & & & & \\
\hline$<50$ & 22,824 & 56 & &, 136 & 39 & 39,461 & 52 & ( & 0 & 0 & 0 & 0 & & 12,047 & 32 \\
\hline $50-59$ & 12,936 & 32 & &, 794 & 34 & 17,049 & 23 & & 35,262 & 46 & 2058 & 37 & & 12,560 & 33 \\
\hline $60-69$ & 5022 & 12 & &, 150 & 23 & 12,553 & 17 & & 26,685 & 35 & 3534 & 63 & & 13,108 & 34 \\
\hline$\geq 70$ & 0 & 0 & & 48 & 4 & 5972 & 8 & & 14,934 & 19 & 40 & $<1$ & & 548 & 1 \\
\hline TNM stage & & & & & & & & & & & & & & & \\
\hline Invasive & 7 & 14 & $\mathrm{~N}$ & A & N/A & 6 & 86 & & 121 & 35 & 443 & 52 & & 232 & 45 \\
\hline $\begin{array}{l}\text { Non- } \\
\text { invasive }\end{array}$ & 50 & 86 & & A & N/A & 1 & 14 & & 229 & 65 & 409 & 48 & & 288 & 55 \\
\hline Smoking stat & & & & & & & & & & & & & & & \\
\hline $\begin{array}{l}\text { Never } \\
\text { smoker }\end{array}$ & 22,599 & 55 & &, 205 & 49 & 41,948 & 56 & & 36,478 & 47 & 1848 & 33 & & 22,057 & 58 \\
\hline $\begin{array}{l}\text { Former } \\
\text { smoker }\end{array}$ & 7207 & 18 & &, 410 & 27 & 23,924 & 32 & & 33,931 & 44 & 2018 & 36 & & 11,848 & 31 \\
\hline
\end{tabular}


Table 1 (continued)

\begin{tabular}{|c|c|c|c|c|c|c|c|c|c|c|c|c|}
\hline \multirow[t]{2}{*}{ Study } & \multicolumn{2}{|c|}{ Spain (EPIC) } & \multicolumn{2}{|c|}{ Sweden (EPIC) } & \multicolumn{2}{|c|}{$\begin{array}{l}\text { United Kingdom } \\
\text { (EPIC) }\end{array}$} & \multicolumn{2}{|c|}{ USA (VITAL) } & \multicolumn{2}{|c|}{ Netherlands (NLCS) } & \multicolumn{2}{|c|}{$\begin{array}{l}\text { Australia } \\
(\mathrm{MCCS})^{\mathrm{b}}\end{array}$} \\
\hline & No. & $\%^{\mathrm{a}}$ & No. & $\%$ & No. & $\%^{\mathrm{a}}$ & No. & $\%^{\mathrm{a}}$ & No. & $\%^{\mathrm{a}}$ & No. & $\%^{\mathrm{a}}$ \\
\hline $\begin{array}{l}\text { Current } \\
\text { smoker }\end{array}$ & 10,976 & 27 & 11,713 & 24 & 9163 & 12 & 6490 & 9 & 1766 & 31 & 4358 & 11 \\
\hline \multicolumn{13}{|l|}{ MDS } \\
\hline $0-3$ & 20,067 & 49 & 13,466 & 27 & 24,162 & 32 & 29,434 & 39 & 2181 & 39 & 22,326 & 59 \\
\hline $4-5$ & 17,231 & 42 & 25,798 & 52 & 29,122 & 39 & 29,194 & 39 & 2409 & 43 & 10,411 & 27 \\
\hline $6-9$ & 3484 & 9 & 10,064 & 21 & 21,751 & 29 & 15,921 & 22 & 1042 & 18 & 5314 & 14 \\
\hline
\end{tabular}

EPIC European prospective investigation into cancer and nutrition, NLCS Netherlands Cohort Study, VITAL VITamins And Lifestyle Study, MCCS Melbourne Collaborative Cohort Study, TNM stage tumour nodes metastasis stage, MIBC muscle-invasive bladder cancer, NMIBC nonmuscle-invasive bladder cancer

${ }^{\mathrm{a}}$ The sum does not add up to the total, because of missing values

${ }^{b}$ Recruitment of the MCCS is still ongoing, therefore the presented number of participants differ from the 2016- and 2017-published numbers by Dugue et al.

Table 2 Pooled HR and 95\% CI for the association between adherence to the Mediterranean diet and risk of developing bladder cancer for all bladder cancer, by sex, and by disease sub-type

\begin{tabular}{|c|c|c|c|c|c|c|c|c|c|}
\hline \multirow[t]{2}{*}{ Diet score ${ }^{\mathrm{a}}$} & \multicolumn{3}{|l|}{ Both sexes } & \multicolumn{3}{|l|}{ Male } & \multicolumn{3}{|l|}{ Female } \\
\hline & $\begin{array}{l}\text { Cases/person- } \\
\text { time }^{\text {b }}\end{array}$ & Pooled HR & $95 \% \mathrm{CI}$ & $\begin{array}{l}\text { Cases/person- } \\
\text { time }^{\mathrm{a}}\end{array}$ & Pooled HR & $95 \% \mathrm{CI}$ & $\begin{array}{l}\text { Cases/person- } \\
\text { time }^{\mathrm{a}}\end{array}$ & Pooled HR & $95 \% \mathrm{CI}$ \\
\hline \multicolumn{10}{|c|}{ All bladder cancer ${ }^{c}$} \\
\hline Low $(0-3)$ & $1483 / 2,460,613$ & 1.00 & Reference & $1082 / 756,521$ & 1.00 & Reference & $399 / 1,703,192$ & 1.00 & Reference \\
\hline Medium (4-5) & $1479 / 2,868,685$ & 0.91 & $0.85-0.99$ & $1113 / 951,445$ & 0.89 & $0.82-0.97$ & $340 / 1,920,564$ & 0.84 & $0.73-0.98$ \\
\hline High (6-9) & $619 / 1,247,881$ & 0.85 & $0.77-0.93$ & $498 / 462,294$ & 0.86 & $0.77-0.96$ & 149/783,160 & 0.90 & $0.74-1.10$ \\
\hline $\begin{array}{l}\text { MDS continu- } \\
\text { ous }\end{array}$ & $3581^{\mathrm{d}} / 6,577,179$ & 0.96 & $0.94-0.98$ & $2693 / 2,170,260$ & 0.95 & $0.93-0.98$ & $888 / 4,406,918$ & 0.96 & $0.92-1.00$ \\
\hline \multicolumn{10}{|c|}{ Non-muscle-invasive } \\
\hline Low $(0-3)$ & $643 / 2,156,174$ & 1.00 & Reference & $484 / 652,250$ & 1.00 & Reference & $176 / 1,449,731$ & 1.00 & Reference \\
\hline Medium (4-5) & $620 / 2,256,426$ & 0.93 & $0.83-1.04$ & $446 / 748,953$ & 0.82 & $0.72-0.94$ & $138 / 1,510,539$ & 0.86 & $0.68-1.09$ \\
\hline High (6-9) & $251 / 933,699$ & 0.86 & $0.74-0.99$ & $212 / 370,334$ & 0.87 & $0.74-1.03$ & $58 / 614,493$ & 0.94 & $0.69-1.29$ \\
\hline $\begin{array}{l}\text { MDS continu- } \\
\text { ous }\end{array}$ & $1514 / 5,346,298$ & 0.96 & $0.94-0.99$ & $1142 / 1,771,536$ & 0.96 & $0.92-0.99$ & $372 / 3,574,763$ & 0.97 & $0.92-1.04$ \\
\hline \multicolumn{10}{|l|}{ Muscle-invasive } \\
\hline Low $(0-3)$ & $408 / 1,291,420$ & 1.00 & Reference & $326 / 475,555$ & 1.00 & Reference & $87 / 796,549$ & 1.00 & Reference \\
\hline Medium (4-5) & $355 / 1,427,419$ & 0.88 & $0.76-1.02$ & $279 / 570,121$ & 0.80 & $0.68-0.95$ & $73 / 850,470$ & 0.99 & $0.70-1.38$ \\
\hline High (6-9) & $167 / 625,505$ & 0.89 & $0.74-1.07$ & $132 / 290,429$ & 0.85 & $0.69-1.05$ & $33 / 316,218$ & 1.05 & $0.68-1.60$ \\
\hline $\begin{array}{l}\text { MDS continu- } \\
\text { ous }\end{array}$ & $930 / 3,344,345$ & 0.94 & $0.90-0.97$ & $737 / 1,336,106$ & 0.94 & $0.90-0.98$ & $193 / 2,008,238$ & 0.95 & $0.88-1.04$ \\
\hline
\end{tabular}

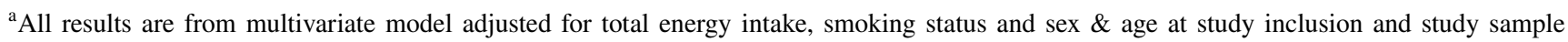
through setting of survival time

${ }^{\mathrm{b}}$ Total number of cases in adherence category may change by sex, because adherence is calculated separately in each stratum

${ }^{\mathrm{c}}$ Number of cases do not add up, because of missing values on stage at diagnosis

${ }^{\mathrm{d}}$ Total number of cases in analysis (3.581) lower than Table 1 (3.590) because of missing values in energy intake and/or MDS score

those in ever smokers $\left(\mathrm{HR}_{\text {high }} 0.80,[95 \%\right.$ CI $0.71,0.89]$, $\mathrm{HR}_{\text {medium }} 0.90$, [95\% CI $\left.\left.0.83,0.98\right]\right)$.

Results remained consistently below 1.00 for nonmuscle-invasive $\left(\mathrm{HR}_{\text {high }} 0.86\right.$ [95\% CI 0.74, 0.99]) and muscle-invasive ( $\mathrm{HR}_{\text {high }} 0.89$ [95\% CI 0.74, 1.07]) patients after stratification on disease sub-type (Table 2).

Results for men ( $\mathrm{HR}_{\text {high }} 0.86$ [95\% CI 0.77-0.96], $\mathrm{HR}_{\text {medium }} 0.89$ [95\% CI 0.82, 0.97]) and women $\left(\mathrm{HR}_{\text {high }}\right.$ 


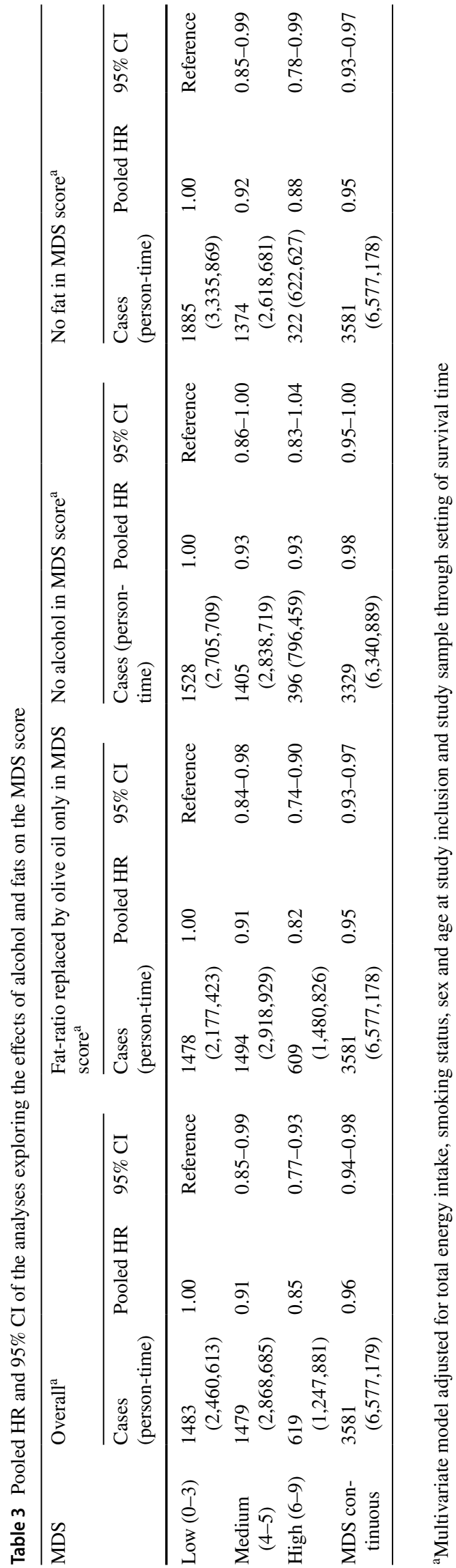

0.90 [95\% CI 0.74-1.10], $\mathrm{HR}_{\text {medium }} 0.84$ [95\% CI 0.73 , $0.98])$ were comparable and in line with the overall estimates. Although total person-time was higher for women, the total number of cases was much higher for men (Table 2). When stratified on both disease sub-type and sex, HRs were consistently below 1.00, except for high compared with low adherence to the Mediterranean diet and risk of muscle-invasive disease for women $\left(\mathrm{HR}_{\text {high }}\right.$ 1.05 [95\% CI 0.68, 1.60]) (Table 2).

In the exploratory analysis, we obtained similar results after excluding either fats $\left(\mathrm{HR}_{\text {high }} 0.88\right.$ [95\% CI 0.78, 0.99], $\mathrm{HR}_{\text {medium }} 0.92$ [95\% CI $\left.\left.0.85,0.99\right]\right)$ or alcohol $\left(\mathrm{HR}_{\text {high }} 0.93\right.$ [95\% CI 0.83, 1.04], $\mathrm{HR}_{\text {medium }} 0.93$ [95\% CI 0.86, 1.00]) from the diet score. Also, consistent results were found in the relation between adherence to the Mediterranean diet and bladder cancer risk when we replaced the lipid ratio (fats from plant sources divided by total fats) with olive oil intake only $\left(\mathrm{HR}_{\text {high }} 0.82\right.$ [95\% CI 0.74, 0.90], $\mathrm{HR}_{\text {medium }} 0.91$ [95\% CI 0.84, 0.98]).

\section{Discussion}

\section{Main findings}

We investigated the association between adherence to the Mediterranean diet and bladder cancer risk and observed an overall inverse association between a high adherence to the Mediterranean diet and the risk of developing bladder cancer. Analyses stratified by sex and disease sub-type showed similar results, indicating that the association is unlikely to be confounded by factors that might differ between these subgroups.

Previously published results from studies that have investigated the association between adherence to the Mediterranean diet and the risk of developing bladder cancer are in line with our findings. Although not statistically significant, Buckland et al. [27] reported inverse associations between adherence to the Mediterranean diet and risk of overall, aggressive or non-aggressive bladder cancer for men and women. In contrast to our association between Mediterranean dietary adherence and non-muscle-invasive disease, Dugué et al. [28], based on the MCCS, found a weak inverse association between adherence to the Mediterranean diet and urothelial cell carcinoma only. It is worth mentioning that these two studies [27, 28] used different dietary fat assessment measures for the Mediterranean diet. Buckland et al. also used a different grading score for determining dietary adherence.

Despite the limited evidence for a role of the Mediterranean diet in the development of bladder cancer overall, several studies have focused on some key elements of this dietary pattern and found some beneficial effects. For example, 
it has been shown that the consumption of vegetables and fruits is inversely associated with the risk of bladder cancer $[9,49]$. This finding is not unexpected, since both vegetables and fruits contain large quantities of polyphenols, carotenoids, and vitamins $\mathrm{C}$ and $\mathrm{E}$, which have antioxidant functions, allowing them to prevent DNA damage by neutralizing reactive oxygen species $[50,51]$. Conversely, a positive association with the risk of developing bladder cancer has been reported for high consumption of animal products, such as red and processed meats and animal proteins [52-54]. During high-temperature cooking of meat, specific substances which are known to be involved in bladder cancer carcinogenesis are formed [55]. In addition, red meat is rich in iron, which is associated with increased formation of $\mathrm{N}$-nitroso compounds (NOCs). These compounds have been suggested to induce tumours in the bladder [56].

While reportedly lower in saturated and animal fats, the Mediterranean diet is associated with a higher intake of dietary fat (approximately 35\% of total energy intake) usually from monounsaturated dietary fat. Another important element of the Mediterranean diet that has been studied as a single food item in the relation with bladder cancer is olive oil. Both Goulas et al. [57] and Brinkman et al. [58] showed that a higher intake of olive oil reduced bladder cancer risk. Traditionally, it has been thought that the monounsaturated fat component of olive oil was at least partly responsible for the Mediterranean diet's health benefits but, after reviewing our sensitivity analyses using different dietary fats, this does not appear to be the case.

A possible additional explanation for a protective effect of the Mediterranean diet might be the high concentration of polyphenols in olive oil. These dietary factors are well known for their anti-oxidative and anti-inflammatory properties [59, 60]. In addition, polyphenols have been shown to have a beneficial effect on cellular function [61]. Since processes such as deregulated cell proliferation and suppressed cell death often provide a basis for tumour progression, polyphenols in olive oil may help to protect the cells of the bladder membrane against further metastasis [61]. High concentrations of polyphenols can also be found in wine, which is the main source of alcohol consumption in Mediterranean regions. Although it was expected that high concentrations of polyphenols from olive oil and wines could explain the beneficial effect of adhering to the Mediterranean diet on bladder cancer risk, it was not evident from our analyses. Therefore, more detailed analysis on polyphenols and other components of the Mediterranean diet in their relation to bladder cancer risk is needed to help explain the beneficial effect of high adherence.

Although BLEND is the largest known pooled cohort study investigating associations between adherence to the Mediterranean diet and risk of developing bladder cancer, with enough statistical power to permit detailed analyses and to detect smaller effects, it has several limitations. First, limited information was available for other possible risk factors for bladder cancer, such as body mass index, physical inactivity, socioeconomic status, and occupational exposures to carcinogenic chemicals. Adjustments for these factors could have influenced our results. Nevertheless, the current literature suggests only a small proportion of bladder cancer cases can be attributed to these factors [62-64]. The study of Buckland et al. [27] found a significantly inverse association for current smokers after stratification for smoking status. We repeated this stratified analysis using our data, and although the inverse association of a high adherence to the MDS and bladder cancer was only statistically significant in ever smokers $\left(\mathrm{HR}_{\text {high }} 0.80\right.$, [95\% CI 0.71, 0.89]), the stratified HR estimates did not seem to differ substantially between never smokers and ever smokers.

Another limitation of our study includes potential misclassification of frequency of food consumption derived from food frequency questionnaires (FFQs), which could lead to systematic and random error when estimating adherence to the Mediterranean diet within individual studies [65]. Also, we were not able to take into account any possible changes of dietary and lifestyle habits over time, which could lead to misclassification of long-term diet. As previously reported by Dugué et al. [28], using dietary scores does not overcome the limitations inherent to FFQs, but they may help to distinguish between individuals rather than using absolute amounts of specific foods. Lastly, most of the included cohort studies used self-reported questionnaires for the ascertainment of bladder cancer diagnosis. Previous research showed that gathering diagnostic cancer information by the use of self-reported questionnaires could lead to large amounts of false negative findings, that is, cases would be falsely classified as being a non-case [66]. This could have led to underestimation of the true association.

\section{Conclusion}

We found evidence that high adherence to the Mediterranean diet was associated with a reduced risk of developing bladder cancer. We could not isolate any particular subgroup of foods (e.g. fats, alcohol) from the MDS that provided a greater benefit over others. This may be because it describes the overall effect of the combined factors of the dietary pattern to be most protective.

Acknowledgements None. No funding to declare.

\section{Compliance with ethical standards}

Conflict of interest On behalf of all authors, the corresponding author states that there is no conflict of interest. 
Open Access This article is distributed under the terms of the Creative Commons Attribution 4.0 International License (http://creativeco mmons.org/licenses/by/4.0/), which permits unrestricted use, distribution, and reproduction in any medium, provided you give appropriate credit to the original author(s) and the source, provide a link to the Creative Commons license, and indicate if changes were made.

\section{References}

1. National Cancer Institute (2018) SEER Cancer Stat Fact Sheets: Bladder cancer. https://seer.cancer.gov/statfacts/html/urinb.html. Accessed 14 Nov 2017

2. Svatek RS, Hollenbeck BK, Holmang S et al (2014) The economics of bladder cancer: costs and considerations of caring for this disease. Eur Urol 66:253-262. https://doi.org/10.1016/j.eurur o.2014.01.006

3. Antoni S, Ferlay J, Soerjomataram I et al (2017) Bladder cancer incidence and mortality: a global overview and recent trends. Eur Urol 71:96-108. https://doi.org/10.1016/j.eururo.2016.06.010

4. Freedman ND, Silverman DT, Hollenbeck AR et al (2011) Association between smoking and risk of bladder cancer among men and women. JAMA 306:737-745. https://doi.org/10.1001/ jama.2011.1142

5. Zeegers MP, Volovics A, Dorant E et al (2001) Alcohol consumption and bladder cancer risk: results from The Netherlands Cohort Study. Am J Epidemiol 153:38-41

6. Piyathilake C (2016) Dietary factors associated with bladder cancer. Investig Clin Urol 57(Suppl 1):S14-S25. https://doi. org/10.4111/icu.2016.57.S1.S14

7. Brinkman M, Zeegers MP (2008) Nutrition, total fluid and bladder cancer. Scand J Urol Nephrol. https://doi.org/10.1080/03008 880802285073

8. Zeegers MP, Goldbohm RA, van den Brandt PA (2001) Consumption of vegetables and fruits and urothelial cancer incidence: a prospective study. Cancer Epidemiol Biomark Prev 10:1121-1128

9. Park SY, Ollberding NJ, Woolcott CG et al (2013) Fruit and vegetable intakes are associated with lower risk of bladder cancer among women in the Multiethnic Cohort Study. J Nutr 143:12831292. https://doi.org/10.3945/jn.113.174920

10. Catsburg CE, Gago-Dominguez M, Yuan JM et al (2014) Dietary sources of $\mathrm{N}$-nitroso compounds and bladder cancer risk: findings from the Los Angeles bladder cancer study. Int J Cancer 134:125-135. https://doi.org/10.1002/ijc.28331

11. Hu FB (2002) Dietary pattern analysis: a new direction in nutritional epidemiology. Curr Opin Lipidol 13:3-9

12. Bo S, Ponzo V, Goitre I et al (2016) Predictive role of the Mediterranean diet on mortality in individuals at low cardiovascular risk: a 12-year follow-up population-based cohort study. J Transl Med 14:91. https://doi.org/10.1186/s12967-016-0851-7

13. Mourouti N, Panagiotakos DB (2016) The beneficial effect of a Mediterranean diet supplemented with extra virgin olive oil in the primary prevention of breast cancer among women at high cardiovascular risk in the PREDIMED Trial. Evid Based Nurs 19:71. https://doi.org/10.1136/ebnurs-2016-102303

14. Stefler D, Malyutina S, Kubinova R et al (2015) Mediterranean diet score and total and cardiovascular mortality in Eastern Europe: the HAPIEE study. Eur J Nutr. https://doi.org/10.1007/ s00394-015-1092-X

15. Tuttolomondo A, Casuccio A, Butta C et al (2015) Mediterranean Diet in patients with acute ischemic stroke: Relationships between Mediterranean Diet score, diagnostic subtype, and stroke severity index. Atherosclerosis 243:260-267. https://doi.org/10.1016/j. atherosclerosis.2015.09.017
16. Schwingshackl L, Hoffmann G (2015) Adherence to Mediterranean diet and risk of cancer: an updated systematic review and meta-analysis of observational studies. Cancer Med 4:1933-1947. https://doi.org/10.1002/cam4.539

17. Bosetti C, Turati F, Dal Pont A et al (2013) The role of Mediterranean diet on the risk of pancreatic cancer. Br J Cancer 109:1360 1366. https://doi.org/10.1038/bjc.2013.345

18. Trichopoulou A, Lagiou P (1997) Healthy traditional Mediterranean diet: an expression of culture, history, and lifestyle. Nutr Rev 55:383-389

19. Kennedy ET, Ohls J, Carlson S, Fleming K (1995) The Healthy Eating Index: design and applications. J Am Diet Assoc 95:11031108. https://doi.org/10.1016/S0002-8223(95)00300-2

20. American Institute for Cancer Research (2007) World Cancer Research Fund/American Institute for Cancer Research: food, nutrition, physical activity and the prevention of cancer: a global perspective. American Institute for Cancer Research, Washington D.C.

21. Shivappa N, Steck SE, Hurley TG et al (2014) Designing and developing a literature-derived, population-based dietary inflammatory index. Public Health Nutr 17:1689-1696. https://doi. org/10.1017/S1368980013002115

22. Bagnardi V, Rota M, Botteri E et al (2015) Alcohol consumption and site-specific cancer risk: a comprehensive dose-response meta-analysis. Br J Cancer 112:580-593. https://doi.org/10.1038/ bjc. 2014.579

23. Chow W-H, Dong LM, Devesa SS (2010) Epidemiology and risk factors for kidney cancer. Nat Rev Urol 7:245-257. https://doi. org/10.1038/nrurol.2010.46

24. Guggenheim DE, Shah MA (2013) Gastric cancer epidemiology and risk factors. J Surg Oncol 107:230-236. https://doi. org/10.1002/jso.23262

25. Nelson HD, Zakher B, Cantor A et al (2012) Risk factors for breast cancer for women aged 40 to 49 years: a systematic review and meta-analysis. Ann Intern Med 156:635-648. https://doi. org/10.7326/0003-4819-156-9-201205010-00006

26. Zeegers MP, Tan FE, Verhagen AP et al (1999) Elevated risk of cancer of the urinary tract for alcohol drinkers: a meta-analysis. Cancer Causes Control 10:445-451

27. Buckland G, Ros MM, Roswall N et al (2014) Adherence to the Mediterranean diet and risk of bladder cancer in the EPIC cohort study. Int J cancer 134:2504-2511. https://doi.org/10.1002/ ijc. 28573

28. Dugue P-A, Hodge AM, Brinkman MT et al (2016) Association between selected dietary scores and the risk of urothelial cell carcinoma: a prospective cohort study. Int J cancer 139:1251-1260. https://doi.org/10.1002/ijc.30175

29. Tjonneland A, Olsen A, Boll K et al (2007) Study design, exposure variables, and socioeconomic determinants of participation in diet, cancer and health: a population-based prospective cohort study of 57,053 men and women in Denmark. Scand J Public Health 35:432-441. https://doi.org/10.1080/14034940601047986

30. Clavel-Chapelon F, van Liere MJ, Giubout C et al (1997) E3N, a French cohort study on cancer risk factors. E3N Group. Etude Epidemiologique aupres de femmes de l'Education Nationale. Eur J Cancer Prev 6:473-478

31. Boeing H, Korfmann A, Bergmann MM (1999) Recruitment procedures of EPIC-Germany. European Investigation into Cancer and Nutrition. Ann Nutr Metab 43:205-215. https://doi.org/12787

32. Riboli E, Hunt KJ, Slimani N et al (2002) European Prospective Investigation into Cancer and Nutrition (EPIC): study populations and data collection. Public Health Nutr 5:1113-1124. https://doi. org/10.1079/PHN2002394

33. Panico S, Dello Iacovo R, Celentano E et al (1992) Progetto ATENA, a study on the etiology of major chronic diseases in 
women: design, rationale and objectives. Eur J Epidemiol 8:601-608

34. Beulens JWJ, Monninkhof EM, Verschuren WMM et al (2010) Cohort profile: the EPIC-NL study. Int J Epidemiol 39:11701178. https://doi.org/10.1093/ije/dyp217

35. Lund E, Dumeaux V, Braaten T et al (2008) Cohort profile: the Norwegian Women and Cancer Study-NOWAC-Kvinner og kreft. Int J Epidemiol 37:36-41. https://doi.org/10.1093/ije/dym137

36. Roswall N, Sandin S, Adami H-O, Weiderpass E (2015) Cohort profile: the Swedish Women's Lifestyle and Health cohort. Int J Epidemiol. https://doi.org/10.1093/ije/dyv089

37. Manjer J, Carlsson S, Elmstahl S et al (2001) The Malmo diet and cancer study: representativity, cancer incidence and mortality in participants and non-participants. Eur J Cancer Prev 10:489-499

38. Brannstrom I, Weinehall L, Persson LA et al (1993) Changing social patterns of risk factors for cardiovascular disease in a Swedish community intervention programme. Int J Epidemiol 22:1026-1037

39. Davey GK, Spencer EA, Appleby PN et al (2003) EPIC-Oxford: lifestyle characteristics and nutrient intakes in a cohort of 33883 meat-eaters and 31546 non meat-eaters in the UK. Public Health Nutr 6:259-269. https://doi.org/10.1079/PHN2002430

40. Day N, Oakes S, Luben R et al (1999) EPIC-Norfolk: study design and characteristics of the cohort. European Prospective Investigation of Cancer. Br J Cancer 80(Suppl 1):95-103

41. White E, Patterson RE, Kristal AR et al (2004) VITamins And Lifestyle cohort study: study design and characteristics of supplement users. Am J Epidemiol 159:83-93

42. Giles GG, English DR (2002) The Melbourne collaborative cohort study. IARC Sci Publ 156:69-70

43. Milne RL, Fletcher AS, MacInnis RJ et al (2017) Cohort profile: the Melbourne collaborative cohort study (Health 2020). Int J Epidemiol. https://doi.org/10.1093/ije/dyx085

44. Goossens ME, Isa F, Brinkman M et al (2016) International pooled study on diet and bladder cancer: the bladder cancer, epidemiology and nutritional determinants (BLEND) study: design and baseline characteristics. Arch Public Health 74:30. https://doi. org/10.1186/s13690-016-0140-1

45. Kohlmeier L (1992) The Eurocode 2 food coding system. Eur J Clin Nutr 46(Suppl 5):S25-S34

46. Trichopoulou A, Costacou T, Bamia C, Trichopoulos D (2003) Adherence to a Mediterranean diet and survival in a Greek population. N Engl J Med 348:2599-2608. https://doi.org/10.1056/ NEJMoa025039

47. Schoenfeld D (1982) Partial residuals for the proportional hazards regression model. Biometrika 69:239-241. https://doi. org $/ 10.2307 / 2335876$

48. StataCorp LP (1985) Stata user's guide. Stata Press Stata-Corp LP, College Station

49. Vieira AR, Vingeliene S, Chan DSM et al (2015) Fruits, vegetables, and bladder cancer risk: a systematic review and meta-analysis. Cancer Med 4:136-146. https://doi.org/10.1002/cam4.327

50. Perez-Jimenez J, Diaz-Rubio ME, Saura-Calixto F (2015) Contribution of macromolecular antioxidants to dietary antioxidant capacity: a study in the spanish mediterranean diet. Plant Foods Hum Nutr 70:365-370. https://doi.org/10.1007/s1113 0-015-0513-6
51. Pitsavos C, Panagiotakos DB, Tzima N et al (2005) Adherence to the Mediterranean diet is associated with total antioxidant capacity in healthy adults: the ATTICA study. Am J Clin Nutr 82:694-699

52. Wang C, Jiang H (2012) Meat intake and risk of bladder cancer: a meta-analysis. Med Oncol 29:848-855. https://doi.org/10.1007/ s12032-011-9985-x

53. Li F, An S, Hou L et al (2014) Red and processed meat intake and risk of bladder cancer: a meta-analysis. Int J Clin Exp Med 7:2100-2110

54. Allen NE, Appleby PN, Key TJ et al (2013) Macronutrient intake and risk of urothelial cell carcinoma in the European prospective investigation into cancer and nutrition. Int J Cancer 132:635-644. https://doi.org/10.1002/ijc.27643

55. Ferguson LR (2002) Natural and human-made mutagens and carcinogens in the human diet. Toxicology 181-182:79-82

56. Hughes R, Cross AJ, Pollock JR, Bingham S (2001) Dose-dependent effect of dietary meat on endogenous colonic N-nitrosation. Carcinogenesis 22:199-202

57. Goulas V, Exarchou V, Troganis AN et al (2009) Phytochemicals in olive-leaf extracts and their antiproliferative activity against cancer and endothelial cells. Mol Nutr Food Res 53:600-608. https://doi.org/10.1002/mnfr.200800204

58. Brinkman MT, Buntinx F, Kellen E et al (2011) Consumption of animal products, olive oil and dietary fat and results from the Belgian case-control study on bladder cancer risk. Eur J Cancer 47:436-442. https://doi.org/10.1016/j.ejca.2010.09.027

59. Machowetz A, Poulsen HE, Gruendel S et al (2007) Effect of olive oils on biomarkers of oxidative DNA stress in Northern and Southern Europeans. FASEB J 21:45-52. https://doi.org/10.1096/ fj.06-6328com

60. Fito M, Cladellas M, de la Torre R et al (2008) Anti-inflammatory effect of virgin olive oil in stable coronary disease patients: a randomized, crossover, controlled trial. Eur J Clin Nutr 62:570-574. https://doi.org/10.1038/sj.ejcn.1602724

61. Cicerale S, Conlan XA, Sinclair AJ, Keast RSJ (2009) Chemistry and health of olive oil phenolics. Crit Rev Food Sci Nutr 49:218-236. https://doi.org/10.1080/10408390701856223

62. Madeb R, Messing EM (2004) Gender, racial and age differences in bladder cancer incidence and mortality. Urol Oncol 22:86-92. https://doi.org/10.1016/S1078-1439(03)00139-X

63. Burger M, Catto JWF, Dalbagni G et al (2013) Epidemiology and risk factors of urothelial bladder cancer. Eur Urol 63:234-241. https://doi.org/10.1016/j.eururo.2012.07.033

64. Koebnick C, Michaud D, Moore SC et al (2008) Body mass index, physical activity, and bladder cancer in a large prospective study. Cancer Epidemiol Biomark Prev 17:1214-1221. https://doi. org/10.1158/1055-9965.EPI-08-0026

65. Naska A, Lagiou A, Lagiou P (2017) Dietary assessment methods in epidemiological research: current state of the art and future prospects. F1000Research 6:926. https://doi.org/10.12688/f1000 research.10703.1

66. Navarro C, Chirlaque MD, Tormo MJ et al (2006) Validity of self reported diagnoses of cancer in a major Spanish prospective cohort study. J Epidemiol Commun Health 60:593-599. https:// doi.org/10.1136/jech.2005.039131 


\section{Affiliations}

\section{Willem J. A. Witlox ${ }^{1}$ - Frits H. M. van Osch ${ }^{1,2} \cdot$ Maree Brinkman $^{1,3,11} \cdot$ Sylvia Jochems ${ }^{1,2} \cdot$ Maria E. Goossens $^{4}$. Elisabete Weiderpass ${ }^{5,6,7,8}$. Emily White ${ }^{9}$. Piet A. van den Brandt ${ }^{10}$. Graham G. Giles ${ }^{11,12} \cdot$ Roger L. Milne $^{11,12}$. Inge Huybrechts ${ }^{13} \cdot$ Hans-Olov Adami $^{14,15} \cdot$ Bas Bueno-de-Mesquita $^{16,17,18,19} \cdot$ Anke Wesselius $^{1}$ (D) Maurice P. Zeege rs $^{1,2,20}$}

1 Department of Complex Genetics and Epidemiology, NUTRIM School for Nutrition and Translational Research in Metabolism, Maastricht University, Universiteitssingel 40, 6200 MD Maastricht, The Netherlands

2 Institute of Cancer and Genomic Sciences, University of Birmingham, Birmingham, UK

3 Department of Clinical Studies and Nutritional Epidemiology, Nutrition Biomed Research Institute, Melbourne, Australia

4 Department of General Practice, Katholieke Universiteit Leuven, ACHG-KU Leuven, Kapucijnenvoer 33, Blok J, bus 7001, 3000 Leuven, Belgium

5 Department of Medical Epidemiology and Biostatistics, Karolinska Institutet, Stockholm, Sweden

6 Department of Research, Cancer Registry of Norway, Institute of Population-Based Cancer Research, Oslo, Norway

7 Genetic Epidemiology Group, Folkhälsan Research Center and Faculty of Medicine, University of Helsinki, Helsinki, Finland

8 Department of Community Medicine, Faculty of Health Sciences, University of Troms $\varnothing$, The Arctic University of Norway, Troms $\varnothing$, Norway

9 Fred Hutchinson Cancer Research Center, Seattle, WA, USA

10 Department of Epidemiology, Schools for Oncology and Developmental Biology and Public Health and Primary Care, Maastricht University Medical Centre, Maastricht, The Netherlands
11 Cancer Epidemiology and Intelligence Division, Cancer Council Victoria, Melbourne, VIC, Australia

12 Centre for Epidemiology and Biostatistics, School of Population and Global Health, The University of Melbourne, Melbourne, VIC, Australia

13 International Agency for Research on Cancer (IARC), World Health Organization, Lyon, France

14 Department of Medical Epidemiology and Biostatistics, Karolinska Institutet, Stockholm, Sweden

15 Clinical Effectiveness Research Group, Institute of Health and Society, University of Oslo, Oslo, Norway

16 Department for Determinants of Chronic Diseases (DCD), National Institute for Public Health and the Environment (RIVM), BA Bilthoven, The Netherlands

17 Department of Gastroenterology and Hepatology, University Medical Centre, Utrecht, The Netherlands

18 Department of Epidemiology and Biostatistics, The School of Public Health, Imperial College London, St Mary's Campus, London, UK

19 Department of Social \& Preventive Medicine, Faculty of Medicine, University of Malaya, Kuala Lumpur, Malaysia

20 CAPHRI School for Public Health and Primary Care, University of Maastricht, Maastricht, The Netherlands 